\title{
Status of Rhipicephalus microplus resistance to ivermectin, fipronil and fluazuron in Mato Grosso do Sul, Brazil
}

\author{
Status da resistência de Rhipicephalus microplus a ivermectina, fipronil e \\ fluazuron em Mato Grosso do Sul \\ Luiza Mendes Valsoni'; Mariana Green de Freitas'; Dyego Gonçalves Lino Borges; \\ Fernando de Almeida Borges ${ }^{1 *}$ (1)
}

\begin{abstract}
${ }^{1}$ Laboratório de Doenças Parasitárias, Faculdade de Medicina Veterinária e Ciência Animal, Universidade Federal de Mato Grosso do Sul - UFMS, Campo Grande, MS, Brasil
\end{abstract}

How to cite: Valsoni LM, Freitas MG, Borges DGL, Borges FA. Status of Rhipicephalus microplus resistance to ivermectin, fipronil and fluazuron in Mato Grosso do Sul, Brazil. Braz J Vet Parasito/ 2021; 30(1): e025220. https://doi.org/10.1590/S1984-296120201091

\begin{abstract}
Southern cattle tick resistance to pour-on and injectable acaricides has yet to be evaluated on a broader scope, and the paucity of information on the subject may hinder efforts to control this parasite. The objective of this study was to evaluate the resistance profile of ten populations of Rhipicephalus microplus to the acaricides fluazuron, fipronil and ivermectin in cattle herds in Mato Grosso do Sul, Brazil. The larval immersion test (LIT) was used to evaluate susceptibility to ivermectin and fipronil and the adult immersion test (AIT) was performed to evaluate fluazuron. Samples were randomly obtained in ten farms, and in general, we found resistance in five samples to fluazuron and in four samples to ivermectin and fipronil. Six samples showed incipient resistance to ivermectin and fipronil. Five of the ten evaluated samples showed resistance and/or incipient resistance to all the active ingredients, and the other five to two active ingredients. Among the samples classified as resistant, the average resistance ratio for ivermectin was 2.75 and 3.26 for fipronil. These results demonstrate the advanced status of resistance to the most modern chemical groups for the control of $R$. microplus in the state of Mato Grosso do Sul.
\end{abstract}

Keywords: Acaricides, ticks, chemical control, adult immersion test, larval immersion test.

\section{Resumo}

A resistência do carrapato-do-boi a acaricidas com modo de aplicação "pour-on" e injetáveis é pouco avaliada em estudos mais abrangentes, e essa escassez de informação pode resultar falhas no seu controle. Este estudo teve como objetivo avaliar o perfil de resistência em dez populações de Rhipicephalus microplus aos acaricidas fluazuron, fipronil e ivermectina, em rebanhos bovinos em Mato Grosso do Sul, Brasil. A caracterização fenotípica da resistência foi realizada por meio do teste de imersão de adultos (AIT) para o fluazuron, e teste de imersão de larvas (LIT) para fipronil e ivermectina. As amostras foram obtidas aleatoriamente em dez fazendas, sendo diagnosticada resistência em cinco amostras ao fluazuron e em quatro amostras à ivermectina e fipronil. Seis amostras apresentaram resistência incipiente à ivermectina e fipronil. Cinco das dez amostras avaliadas apresentaram resistência e / ou resistência incipiente a todos os princípios ativos, e as outras cinco a dois princípios ativos. Entre as amostras classificadas como resistentes, a média do fator de resistência para ivermectina foi de 2,75 e de 3,26 para fipronil. Esses resultados demonstram o avançado estado de resistência aos mais modernos grupos químicos para o controle de R. microplus em Mato Grosso do Sul.

Palavras-chave: Acaricidas, carrapatos, controle químico, teste de imersão de adultos, teste de imersão de larvas.

Received November 3, 2020. Accepted December 2, 2020

*Corresponding author: Fernando de Almeida Borges. E-mail: fernando.borges@ufms.br 
The tick Rhipicephalus microplus is an ectoparasite whose preferred hosts are cattle. This parasite causes significant economic losses, such as decreasing milk production, leather damage, reduced weight gain, and immunosuppression. In Brazil, the impact on production caused by R. microplus generates losses of approximately USD 3.2 million per year (Grisi et al., 2014).

The serious situation of resistance to contact-acting tick acaricides in Brazil is widely described in the literature. Most acaricide resistance reports describe the use of spray formulations on the bioassays (reviewed by Higa et al., 2015). However, few studies have reported resistance to pour-on and injectable acaricides, which are the most relevant acaricide formulations used in the current beef cattle production system in Brazil. Pour-on and injectable acaricides are more practical to be used in large herds. Furthermore, the challenge of ticks is increasing in Mato Grosso do Sul state with the shift from raising purebred Zebu to European purebreds (mainly Aberdeen-Angus) and its crossbreds, which are more susceptible to ectoparasites (Bonatte et al., 2019) and this will require to establish tick control procedures that are more intensive in the use of acaricides.

Reck et al. (2014), who standardized the Adult Immersion Test (AIT), were the first researchers to report a fluazuron resistant isolate. Later, four field isolates were characterized in vivo as resistant or with low susceptibility to fluazuron in the states of Minas Gerais, São Paulo and Mato Grosso do Sul (Maciel et al., 2016). Resistance to fipronil was first reported by Castro-Janer et al. (2009), who found that the Larval Immersion Test (LIT) was the most sensitive technique for the diagnosis of resistance. Tick resistance to ivermectin was first reported by Martins \& Furlong (2001) in Rio Grande do Sul based on in vivo testing, and subsequently by Klafke et al. $(2006,2012)$ based on in vitro techniques.

This study aimed to evaluate the resistance profile of Southern cattle tick populations to the acaricides fluazuron, fipronil and ivermectin by in vitro tests in Mato Grosso do Sul, Brazil.

Samples were randomly obtained in ten farms in Mato Grosso do Sul, Brazil, of which it was evaluated whether there was the use of fipronil, fluazuron and ivermectin for the control of ectoparasites. Approximately 150 engorged females were collected at random from more than ten animals on each farm for in vitro testing. The cattle had not been treated with any acaricide in the last 60 days prior to sampling. Upon arrival at the lab, the engorged females were washed in running water, dried with paper towels, and an aliquot of 120 ticks was separated for the AIT, while the remainder were placed on Petri dishes in an incubator for oviposition at $27^{\circ} \mathrm{C}$ for the LIT.

Paired tests were performed using the Porto Alegre (POA) strain as a susceptible reference in the in vitro tests. This isolate was maintained at the Federal University of Mato Grosso do Sul (UFMS) by means of weekly controlled infestations on a calf housed in an individual stall. The protocol was approved by the UFMS Ethics Committee on the Use of Animals (protocol number: 771/2016).

All reagents were analytical grade purity: fluazuron, fipronil ( $\geq 98 \% \mathrm{HPLC}$, donated by Ouro Fino Saúde Animal ${ }^{\circledR}$, Brasil) and ivermectin (Sigma Chemical Co., St. Louis, MO, USA).

Fluazuron was assessed by AIT, using the technique standardized by Reck et al. (2014). The test was performed on 120 engorged females, which were randomly separated into groups of 10 and immersed in concentrations of $500,50,5,0.5$ and $0.05 \mathrm{ppm}$ of fluazuron for 1 minute, followed by an evaluation of oviposition and larval hatching. All the tests were performed in duplicate.

The LIT was performed to evaluate ivermectin (Klafke et al., 2012) and fipronil (Castro-Janer et al., 2009). We have made a modification in both tests: instead of placing 100 larvae directly into microtubes, approximately 100 eggs $(0.05 \mathrm{~g})$ were placed into microtubes, which were sealed with nylon screens until hatching to achieve greater precision. Fipronil was evaluated at concentrations of 3, 2.5, 2, 1.7, 1.2, 1, 0.8, 0.6, 0.5, 0.4 and 0.2 ppm, while ivermectin was evaluated at concentrations of $100,70,49,34.3,24,16.8,11.7,8.2,5.7,4$ and 2.8 ppm. The larval immersion tests were performed in triplicate.

The same diluent used to prepare the immersion solutions was used as negative control in all the AIT and LIT tests. Engorged females and larvae of the POA strain were used as a susceptible reference in all the paired tests.

The index of fecundity (IFEC) for each treatment with fluazuron was calculated according to Castro-Janer et al. (2009), where:

Index of Fertility (IFer) = weight of eggs $(\mathrm{g}) /$ weight of engorged females $(\mathrm{g})$

Index of Fecundity $(\mathrm{IFec})=$ IFer $\mathrm{x}$ hatchability $(\%) / 100$

The IFec values were subjected to one-way analysis of variance, followed by Sidak's multiple comparisons test. Field samples of engorged females showing a significantly higher index of fecundity (IFec) than the susceptible strain at any fluazuron concentration were considered fluazuron resistant. 
Dose vs. response sigmoid curves were constructed by non-linear regression for the log-transformed concentrations and larval mortality expressed as percentages to estimate a median lethal concentration (LC50). The Resistance Ratio (RR) was calculated as the ratio of LC50 values of the field sample and the POA strain. A sample was considered susceptible when the lethal concentration showed no statistical difference from the susceptible strain, based on the overlap of $\mathrm{Cl} 95 \%$ of LC50; while incipient resistance was considered when the lethal concentration differed statistically from the susceptible strain and showed a RR $<2$; and resistant when the lethal concentration was statistically higher than the susceptible strain and with a RR >2 (Castro-Janer et al., 2009).

All the analyses were performed using the GraphPad Prism version 6.0 software (GraphPad Software Inc., San Diego, CA, USA).

Four cattle farms (samples MIG, PED, JUL and BOA) had a history of use of fipronil, fluazuron and ivermectin to control ectoparasites; two famrs (CIC and CLA) used ivermectin and fluazuron; one farm (HOR) used ivermectin and fipronil, and other two farms (REN and ESP) had used only ivermectin. No information regarding the use of acaricides in farm JOS was available. Therefore, in general, ivermectin had already been used in nine of the evaluated farms to control both ecto and endoparasites; fluazuron in six, and fipronil in five.

The AIT with fluazuron revealed resistance at five farms in the state of Mato Grosso do Sul (MIG, ESP, JUL, REN and JOS), as indicated in Figure 1. Four samples (CIC, PED, CLA and BOA) showed even lower IFec values than those of the susceptible reference strain (POA) at some concentrations, demonstrating their susceptibility to fluazuron.

Analyzing the five samples considered resistant to fluazuron, two types of profile were observed: a) at lower concentrations, the Ifec of the field sample was as high as that of the susceptible strain. However, the increase in the concentration of fluazuron did not result in an increase of effectiveness; therefore, in these higher concentrations, Ifec was higher in field samples (ESP, JOS, JUL and MIG); b) in the REN sample, the Ifec of engorged female ticks exposed to the lowest concentrations of fluazuron was higher than that of the susceptible strain; however, the increase in the concentration of fluazuron resulted in an increase in efficacy, no longer differing from the susceptible strain, which could indicate that resistance is still at an early stage. Specifically in the case of this sample, it is not possible to explain the origin of the "initial resistance" according to the farm's history, with no movement of animals and fluazuron was never used to control ticks. In addition, if the same dose-response curve of the POA - strain that was obtained in the paired test with other field samples was used, no significant difference would be observed and the REN sample would be classified as susceptible. Therefore, even if the criterion for the diagnosis of fluazuron resistance (significant difference with the susceptible strain) has been observed, it may be prudent not to classify this sample as resistant, as this difference may have occurred only due to a variation in AIT with fluazuron.

Of the ten field samples evaluated, five were found to be resistant to fluazuron. An analysis of the history of these farms revealed that two of them (MIG and ESP), where resistance to the three active ingredients was detected, had purchased cattle that were already infested from the southern region of the country, where there are numerous reports of acaricide resistance (Martins \& Furlong, 2001; Castro-Janer et al., 2009; Reck et al., 2014; Machado et al., 2014). At the farm where the JUL sample was obtained, fluazuron has been used for many years to control cattle ticks, but no animals have been purchased from other farms. This result leads to the inference that the frequent use of this drug over the years probably resulted in the selection of resistance. The HOR sample, which was susceptible to fluazuron, came from a farm where this active ingredient had never been used and which had not purchased cattle from other farms.

The AIT is performed in a paired test with the susceptible strain, and it requires a large sample of ticks per farm, which is why only a few studies have evaluated the in vitro efficacy of fluazuron. Reck et al. (2014) reported a resistant isolate by the in vitro technique, while Maciel et al. (2016) identified four resistant isolates in field efficacy trials in Minas Gerais, São Paulo and Mato Grosso do Sul. The present study contributes with further reports of fluazuron resistant samples, presenting a part of the current situation of resistance of the Southern cattle tick to this drug in Mato Grosso do Sul.

Tables 1 and 2 show the LC50,95\% Cl and RR obtained by the LIT with fipronil and ivermectin, respectively. Four samples showing resistance and six showing incipient resistance to the two active ingredients were phenotypically characterized. Therefore, no sample could be classified as susceptible to these two acaricides. Among the samples classified as resistant, the average resistance ratio for ivermectin was 2.75 (ranging from 2.09 to 3.10) and 3.26 (2.23 to 4.29) for fipronil.

In two farms (MIG and JUL), where fipronil resistant ticks were found, this active ingredient was used on a weekly basis in their attempt to control ticks. After conducting in vivo bioassays, Souza et al. (2014) reported that the efficacy of fipronil declined from $100 \%$ to $79.3 \%$ over the course of six treatments, demonstrating that resistance to fipronil 

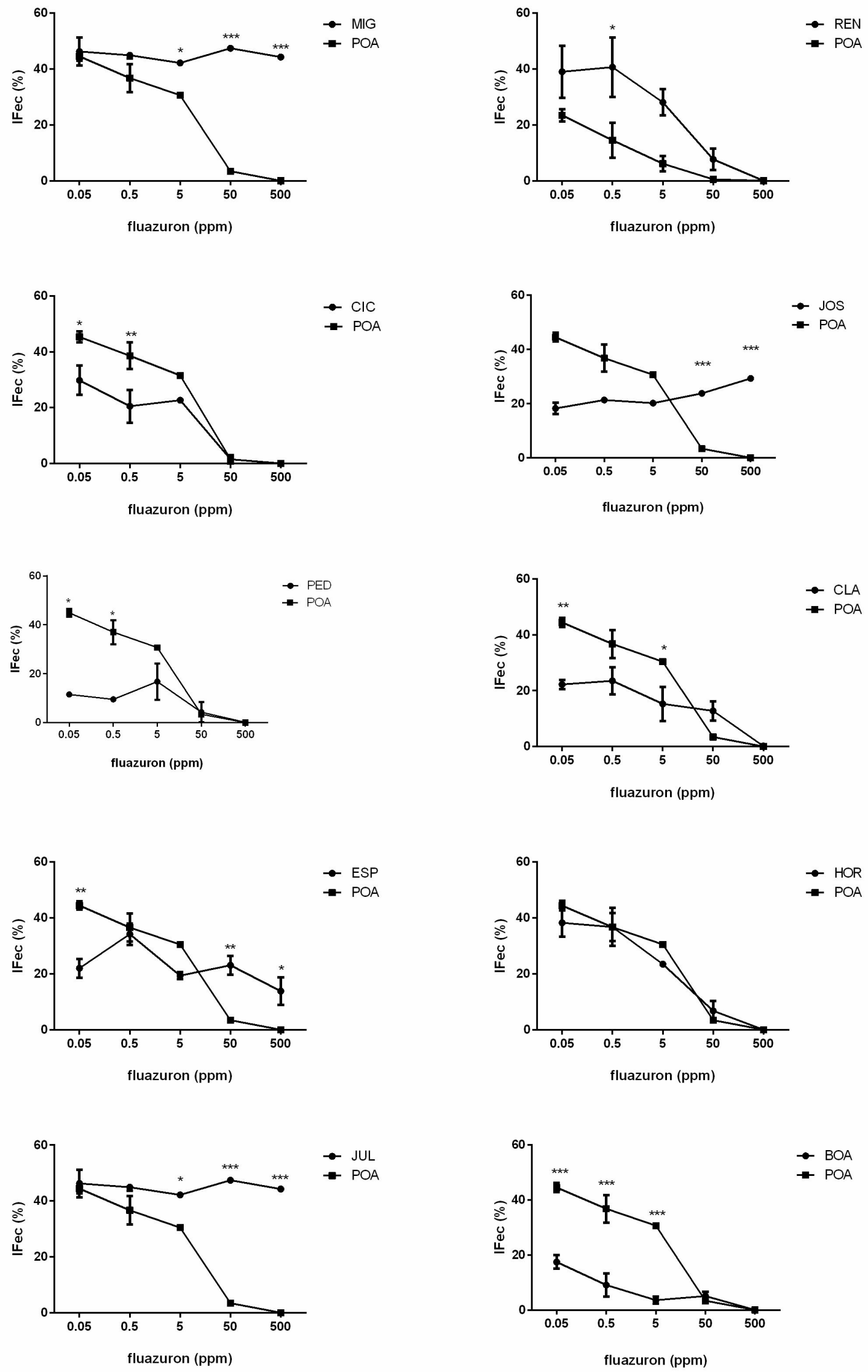

Figure 1. Index of fecundity (IFec) of engorged female ticks exposed to fluazuron Fertility in the Adult Immersion Test of field samples and Porto Alegre strain. Analysis of variance (ANOVA) followed by Bonferroni post test $(* p<0.05, * * p<0.01$ and $* * * p$ $<0.001$ ), comparing field samples (MIG, REN, CIC, JOS, PED, CLA, ESP, HOR, JUL and BOA) with the susceptible reference strain (POA). 
Table 1. Results of the Larval Immersion Test (LIT) with technical grade fipronil on field samples of $R$. microplus compared to the susceptible strain (POA).

\begin{tabular}{|c|c|c|c|c|}
\hline Strain/Sample & $\mathbf{R}^{2}$ & $\mathrm{LC}_{50}(\mathrm{ppm})\left(\mathrm{Cl}_{95}\right)$ & $\mathbf{R R}$ & Status \\
\hline $\mathrm{POA}$ & 0.92 & $1.23(1.15-1.31)$ & - & \\
\hline MIG & 0.80 & $3.92(3.48-4.42)$ & 3.18 & Resistant \\
\hline POA & 0.97 & $0.92(0.77-1.09)$ & - & \\
\hline REN & 0.92 & $1.26(1.11-1.43)$ & 1.36 & Incipient Resistance \\
\hline POA & 0.93 & $1.26(1.18-1.33)$ & - & \\
\hline $\mathrm{CIC}$ & 0.96 & $2.82(2.76-2.89)$ & 2.23 & Resistant \\
\hline POA & 0.92 & $1.23(1.15-1.31)$ & - & \\
\hline JOS & 0.96 & $2.16(2.10-2.22)$ & 1.75 & Incipient Resistance \\
\hline POA & 0.96 & $1.19(1.14-1.25)$ & - & \\
\hline PED & 0.97 & $1.50(1.44-1.56)$ & 1.26 & Incipient Resistance \\
\hline POA & 0.96 & 1.19 (1.14-1.24) & - & \\
\hline CLA & 0.99 & 1.35 (1.33-1.38) & 1.13 & Incipient Resistance \\
\hline POA & 0.92 & $1.20(1.12-1.31)$ & - & \\
\hline ESP & 0.89 & $4.02(3.98-4.11)$ & 3.35 & Resistant \\
\hline POA & 0.97 & $1.18(1.14-1.22)$ & - & \\
\hline HOR & 0.98 & 1.30 (1.27-1.33) & 1.10 & Incipient Resistance \\
\hline POA & 0.92 & $1.20(1.12-1.31)$ & - & \\
\hline JUL & 0.90 & $5.15(4.23-6.28)$ & 4.29 & Resistant \\
\hline POA & 0.91 & $0.72(0.55-1.15)$ & - & \\
\hline BOA & 0.92 & $1.23(1.16-1.31)$ & 1.70 & Incipient Resistance \\
\hline
\end{tabular}

$\mathrm{R}^{2}$ : coefficient of determination; $\mathrm{LC}_{50}$ : lethal concentration for $50 \%$ of the larvae; $\mathrm{Cl}_{95}$ : confidence interval of $95 \%$; RR: resistance factor.

Table 2. Comparison of the lethal concentration of ivermectin for the field samples and the susceptible strain of Rhipicephalus microplus based on the Larval Immersion Test (LIT) with different concentrations of the active ingredient.

\begin{tabular}{|c|c|c|c|c|}
\hline Strain/Sample & $\mathbf{R}^{2}$ & $\mathrm{LC}_{50}(\mathrm{ppm})\left(\mathrm{Cl}_{95}\right)$ & $\mathbf{R R}$ & Status \\
\hline POA & 0.95 & $17.56(16.01-19.26)$ & - & \\
\hline MIG & 0.84 & $54.13(49.10-59.68)$ & 3.08 & Resistant \\
\hline POA & 0.94 & $13.54(10.19-16.81)$ & - & \\
\hline REN & 0.96 & $17.01(15.01-19.27)$ & 1.25 & Incipient Resistance \\
\hline POA & 0.95 & 18.55 (16.84-20.44) & - & \\
\hline $\mathrm{CIC}$ & 0.97 & $57.68(54.91-60.59)$ & 3.10 & Resistant \\
\hline POA & 0.78 & $15.30(12.16-19.26)$ & - & \\
\hline JOS & 0.95 & $17.56(16.09-19.17)$ & 1.14 & Incipient Resistance \\
\hline POA & 0.95 & $17.93(16.07-19.20)$ & - & \\
\hline PED & 0.96 & $33.47(31.07-36.06)$ & 1.86 & Incipient Resistance \\
\hline POA & 0.97 & $14.06(13.01-15.19)$ & - & \\
\hline CLA & 0.95 & 17.56 (16.09-19.17) & 1.24 & Incipient Resistance \\
\hline POA & 0.96 & $17.58(16.06-19.30)$ & - & \\
\hline ESP & 0.91 & $48.14(46.06-53.34)$ & 2.73 & Resistant \\
\hline POA & 0.95 & 17.50 (16.01-19.17) & - & \\
\hline HOR & 0.98 & $20.32(19.49-21.18)$ & 1.16 & Incipient Resistance \\
\hline POA & 0.96 & $17.86(16.56-19.76)$ & - & \\
\hline JUL & 0.95 & $37.40(35.28-39.82)$ & 2.09 & Resistant \\
\hline POA & 0.74 & $13.94(10.74-18.08)$ & - & \\
\hline $\mathrm{BOA}$ & 0.95 & 18.55 (17.09-20.17) & 1.33 & Incipient Resistance \\
\hline
\end{tabular}

$\mathrm{R}^{2}$ : coefficient of determination; $\mathrm{LC}_{50}$ : lethal concentration for $50 \%$ of the larvae; CI95: confidence interval of $95 \%$; RR: resistance ratio. 
is rapidly established in the tick population. Three samples (PED, HOR and BOA) showed incipient resistance to fipronil, which was the drug used at the time of this study at the farms.

This result of $100 \%$ of resistance / incipient resistance to fipronil is the opposite observed in a study conducted in the semi-arid region of Paraíba State, Brazil, in which the same LIT methodology was employed, however, all 22 samples evaluated were susceptible (Vilela et al., 2020). According to these authors, fipronil is still little used in cattle in the semi-arid region of Paraíba State, therefore, the greater use of this molecule on farms in Mato Grosso do Sul could justify this difference in susceptibility profile.

It was observed the existence of resistant (CIC and ESP) and incipient resistant ticks (REN, HOR and CLA) to fipronil, and resistant ticks to fluazuron (ESP) as well, in farms with no historic of use of these acaricides. These results can be interesting to demonstrate the possible origin of the resistance on the farms from where the animals were purchased.

Ivermectin was also used for controlling gastrointestinal nematodes infection in all evaluated farms, which may have contributed to the observed scenario of four resistant samples (MIG, CIC, ESP, JUL) and the other six farms with incipient resistance. Three farms (REN, JOS and BOA) with ticks showing incipient resistance to ivermectin had the same history of use of ivermectin at 30-day intervals for deworming cattle.

Acaricidal resistance was observed in all evaluated samples. Considering the samples classified with incipient resistance within the category of resistance, five samples showed resistance to the three evaluated active ingredients and the other five samples showed resistance to two of the active ingredients.

Although in vitro assays are simple and low cost techniques, during the course of this study, several limitations made it difficult to reproduce these techniques. These limitations included the need to perform each bioassay using a field isolate paired with a susceptible strain, which requires housing infested cattle in individual stalls with biosafety standards to prevent contamination of the isolate, leading to additional expenses for the animals' maintenance. Another obstacle was the use of the technical grade active ingredient, which is more expensive than the commercial product. For the AIT with fluazuron, another limitation is the need of a high number of ticks, which is not always possible to be collected in a farm. Lastly, it is suggested that studies should be conducted to standardize discriminating doses for the detection of resistance to ivermectin, fipronil and fluazuron.

These results demonstrate the advanced status of resistance to the most modern chemical groups for the control of R. microplus in the state of Mato Grosso do Sul, and the need for individual monitoring in each farm as well.

\section{Acknowledgements}

The authors thank Prof. Itabajara da Silva Vaz Junior and the team of the Laboratory of Animal Health and Immunology (UFRGS) for donating the susceptible strain.

\section{References}

Bonatte PJr, Rodrigues VS, Garcia MV, Higa LOS, Zimmermann NP, Barros JC, et al. Economic performance evaluation of Brangus and Nellore cattle breed naturally infested with Rhipicephalus microplus in an extensive production system in Central-West Brazil. Exp Appl Acarol 2019; 78(4): 565-577. http://dx.doi.org/10.1007/s10493-019-00404-1. PMid:31352649.

Castro-Janer E, Rifran L, Piaggio J, Gil A, Miller RJ, Schumaker TTS. In vitro tests to establish LC ${ }_{50}$ and discriminating concentrations for fipronil against Rhipicephalus (Boophilus) microplus (Acari: Ixodidae) and their standardization. Vet Parasitol 2009; 162(1-2): 120-128. http://dx.doi.org/10.1016/j.vetpar.2009.02.013. PMid:19278787.

Grisi L, Leite RC, Martins JRS, Barros ATM, Andreotti R, Cançado PHD, et al. Reassessment of the potential economic impact of cattle parasites in Brazil. Braz J Vet Parasito/ 2014; 23(2): 150-156. http://dx.doi.org/10.1590/S1984-29612014042. PMid:25054492.

Higa LOS, Garcia MV, Barros JC, Koller WW, Andreotti R. Acaricide resistance status of the Rhipicephalus microplus in Brazil: a literature overview. Med Chem 2015; 5(7): 326-333. http://dx.doi.org/10.4172/2161-0444.1000281.

Klafke GM, Castro-Janer E, Mendes MC, Namindome A, Schumaker TTS. Applicability of in vitro bioassays for the diagnosis of ivermectin resistance in Rhipicephalus microplus (Acari: ixodidae). Vet Parasitol 2012; 184(2-4): 212-220. http://dx.doi.org/10.1016/j. vetpar.2011.09.018. PMid:21978742.

Klafke GM, Sabatini GA, Albuquerque TA, MartinsJR, Kemp DH, Miller RJ, et al. Larval immersion tests with ivermectin in populations of the cattle tick Rhipicephalus (Boophilus) microplus (Acari: Ixodidae) from state of Sao Paulo, Brazil. Vet Parasitol 2006; 142(3-4): 386-390. http://dx.doi.org/10.1016/j.vetpar.2006.07.001. PMid:16904265. 
Machado FA, Pivoto FP, Ferreira MST, Gregorio FV, Vogel FSF, Sangioni LS. Rhipicephalus (Boophilus) microplus in the westerncentral region of Rio Grande do Sul, Brazil: multiresistant tick. Braz J Vet Parasito/ 2014; 23(3): 337-342. http://dx.doi.org/10.1590/ S1984-29612014063. PMid:25271453.

Maciel WG, Lopes WDZ, Gomes LVC, Cruz BC, Felippelli G, Santos IBD, et al. Susceptibility of Rhipicephalus (Boophilus) microplus to fluazuron $(2.5 \mathrm{mg} / \mathrm{kg})$ and a combination of novaluron $(2.0 \mathrm{mg} / \mathrm{kg})+$ eprinomectin $(0.36 \mathrm{mg} / \mathrm{kg})$ in field studies in Brazil. Prev Vet Med 2016; 135: 74-86. http://dx.doi.org/10.1016/j.prevetmed.2016.10.019. PMid:27931932.

Martins JR, Furlong J. Avermectin resistance of the cattle tick Boophilus microplus in Brazil. Vet Rec 2001; 149(2): 64. PMid:11488352.

ReckJ, Klafke GM, Webster A, Dall'Agnol B, Scheffer R, Souza UA, et al. First report of fluazuron resistance in Rhipicephalus microplus: a field tick population resistant to six classes of acaricides. Vet Parasitol 2014; 201(1-2): 128-136. http://dx.doi.org/10.1016/j. vetpar.2014.01.012. PMid:24560364.

Souza AP, Paim F, Bellato V, Sartor AA, Moura AB, Rosa LD, et al. Avaliação da eficácia do fipronil em Rhipicephalus (Boophilus) microplus em tratamentos consecutivos. Arq Bras Med Vet Zootec 2014; 66(1): 55-60. http://dx.doi.org/10.1590/S010209352014000100009.

Vilela VLR, Feitosa TF, Bezerra RA, Klafke GM, Riet-Correa F. Multiple acaricide-resistant Rhipicephalus microplus in the semiarid region of Paraíba State, Brazil. Ticks Tick Borne Dis 2020; 11(4): 101413. http://dx.doi.org/10.1016/j.ttbdis.2020.101413. PMid:32173298. 